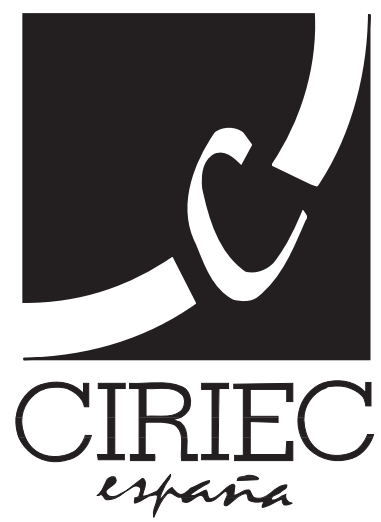

CIRIEC-España, Revista de Economía Pública, Social y Cooperativa, $n^{\circ}$ 88, Diciembre 2016, pp. 61-92

\title{
¿Presentan las cooperativas contextos favorables para la igualdad de género?: Especial referencia a la provincia de Teruel
}

\author{
M. Luisa Esteban Salvador \\ Ana F. Gargallo Castel \\ Francisco Javier Pérez Sanz
}

Universidad de Zaragoza

Cómo citar este artículo / How to cite this article: ESTEBAN, M.L., GARGALLO, A. \& PÉREZ, F.J. (2016): "¿Presentan las cooperativas contextos favorables para la igualdad de género?: Especial referencia a la provincia de Teruel", CIRIEC-España, Revista de Economía Pública, Social y Cooperativa, 88, 61-92.

CIRIEC-España, revista de economía pública, social y cooperativa ISSN edición impresa: 0213-8093. ISSN edición online: 1989-6816.

(C) 2016 CIRIEC-España 


\title{
¿Presentan las cooperativas contextos favorables para la igualdad de género?: Especial referencia a la provincia de Teruel
}

\author{
M. Luisa Esteban Salvador, Ana F. Gargallo Castel y \\ Francisco Javier Pérez Sanz
}

\section{RESUMEN}

Las cooperativas presentan características organizativas y de funcionamiento diferenciales que podrían ofrecer contextos favorables para la igualdad de género. En este trabajo se exponen diferentes aspectos relacionados con las condiciones laborales y de flexibilidad en el trabajo de las mujeres en las cooperativas de un territorio con alta despoblación, como es la provincia de Teruel. A su vez se estudia el papel de los distintos agentes de interés involucrados en estas organizaciones y los potenciales beneficios y ventajas para el desarrollo familiar, personal y profesional de las mujeres en este contexto de la economía social. El mayor conocimiento de los factores sociales y organizativos inherentes a estas organizaciones facilitará el desarrollo de políticas y acciones encaminadas a reforzar proyectos empresariales que contribuyan a integrar las necesidades de las mujeres y las de su entorno. Con esta finalidad se ha llevado a cabo un análisis cualitativo mediante del desarrollo de entrevistas en profundidad, dado que estas aportan información más precisa y extensa que otras metodologías de investigación alternativas. Los resultados aportan evidencia sobre las políticas sociales internas y externas aplicadas, y las relaciones institucionales y empresariales de estas cooperativas, caracterizadas por una alta presencia de mujeres en su gestión y funcionamiento. También se observa que la autogestión permite mayor flexibilidad que otras fórmulas empresariales, en aspectos como la conciliación o las condiciones laborales. Así mismo, las mujeres reconocen que su implicación con la entidad debe ser mayor, dado que su futuro laboral depende de la supervivencia de la cooperativa.

PALABRAS CLAVE: Cooperativas, empleo, mujer, conciliación, España, despoblación.

CLAVES ECONLIT: M14, R12, J01.

Cómo citar este artículo / How to cite this article: ESTEBAN, M.L., GARGALLO, A. \& PÉREZ, F.J. (2016): "¿Presentan las cooperativas contextos favorables para la igualdad de género?: Especial referencia a la provincia de Teruel", CIRIEC-España, Revista de Economía Pública, Social y Cooperativa, 88, 61-92.

Correspondencia: M. Luisa Esteban Salvador, Titular de Universidad; Ana F. Gargallo Castel, Ayudante Doctor, y Francisco Javier Pérez Sanz, Titular de Escuela Universitaria, Facultad de

Ciencias Sociales y Humanas, Universidad de Zaragoza. E-mail de contacto: luisaes@unizar.es 


\section{EXPANDED ABSTRACT}

\section{Do cooperatives have favorable contexts for gender equality?: Special reference to the province of Teruel}

\section{Objectives}

Cooperative enterprises have different organizational and operational characteristics that could provide favorable conditions for gender equality. In this paper, we describe several aspects of the working conditions and workplace flexibility of women in cooperatives in the province of Teruel, a region that is characterized by its low population density. In addition, we study other aspects involved in the running of these organizations in the context of social economy, and how this could have potential benefits and advantages for the personal and professional development of women and their families. A greater understanding of these organizations will facilitate the development of actions aimed at strengthening business projects that contribute to integrate women's needs and the needs of their surrounding environments.

\section{Design/methodology/approach}

A qualitative analysis has been carried out through in-depth interviews, which have provided more detailed and extensive information than other available methodologies. The initial sample consists of 99 cooperatives, representing $31.03 \%$ of the total population of cooperative entities in the province of Teruel, Spain. This sample was then filtered by selecting the cooperatives which have a greater percentage of female employees higher than male employees, or have more female than male directors, including those cooperatives which fulfilled both of these conditions. There resulting set of 12 cooperatives with a large number of female employees among its staff or with high female participation in their boards of directors. We subjected to semi-structured interviews, one per cooperative, of their partners and/or employees, using a semi-structured questionnaire.

\section{Results / Research limitations / Implications}

The results suggest that self-management allows greater flexibility than other forms of enterprise in areas such as conciliation or working conditions. Likewise, women recognize that their involvement with the entity must be greater, since their future employment depends on the survival of the cooperative. One factor that affects the reconciliation of family, work and personal life is the presence or absence of seasonality in the activities carried out by the cooperative. Internal measures for the seasonal adjustment of demand could contribute to improving the reconciliation and also to reducing inequalities between men and women. 
With regard to working conditions, there are opportunities for conciliation and timetable flexibility that rely on the goodwill and the climate of trust existing in the cooperatives. This issue is closely related to the good relations among its members, as evidenced by the opinions of the respondents and the presence of female leadership focused on greater collaboration and teamwork. It is noteworthy that these cordial relations extend even among the companies in the sector. Collaborative attitudes between cooperatives of the same sector of activity are frequent.

Self-management allows the working day to be better and more easily adjusted to the specific needs of female employees as compared to other styles of management. In general, working hours are not cause for concern. Women are aware that if the activity requires a greater time investment, their commitment must be greater, since their future careers depend of the survival of the cooperative

The good relations existing among the different cooperatives in the province are remarkable. The study emphasizes the establishment of mutually supportive relationships with other cooperatives and, in many cases, the use of synergies with the competing companies. This reinforces the expected behaviors for organizations based on inter-cooperation and networking.

Due to the peculiarities of the context in which these cooperatives operate, mainly in rural areas, cooperatives can cover the needs of the partners, boost rural development, to improve trade activities, provide support and advice to access to new foreign markets; improve structures through integration processes and obtain competitive advantages with formulas of inter-cooperation with other groups.

Regarding the support of the public administrations in issues related to paperwork or consultation and advisory services, no conclusive results have been obtained. Relations with public administrations, however, could be improved to take full advantage of the potential of wealth creation in cooperatives and to achieve greater effectiveness of policies of public support for the promotion of female entrepreneurship and social economy entities. The recognition of gender inequalities in the labor and business sphere by the Spanish government, expressed through the Gender Equality Act, should be taken into account when implementing administrative procedures for cooperatives in order to be more sensitive to women's necessities.

Simplification of administrative procedures and a more individualised guidance and advice for female entrepreneurs in the social economy should be included in the agendas of public authorities. These measures become especially sensitive in territories such as Teruel, where the weakness of its business fabric and its relatively high rate of female unemployment are clear components of the economic stagnation of the province.

Some questionnaire answers show that cooperative principles are present in these entities, as is the case in one company where the partners reported being satisfied and happy to contribute to the respect of agriculture and to promote environmental care. 
In addition to the financial income associated with participation in the cooperative, other non-economic "intangible" benefits related to personal satisfaction and fulfilment derived from such participation should be highlighted. This added value must also be taken into account at the time of quantifying the benefits of both cooperatives and the social economy as a whole, and especially when formulating strategy and assessing the results achieved.

\section{Practical conclusions and original value}

The findings show that there is still a long way to go to achieve the reconciliation of personal, family and work life that allows full equality. This issue reveals the need for action, both institutionally, through a suitable framework of support measures, and internally, within the entities themselves, through incentives leading to the full implementation of these cooperative values and rules of conduct.

Our results give new evidence of the internal and external social policies, and of institutional and business relationships of these cooperatives characterized by a high representation of women. It is also noted that self-management allows improve adaptation of the working conditions and flexibility of women in cooperative workplaces. Moreover, they realize that their involvement must be greater, since future employment depends on the survival of the cooperative. It would be interesting for future studies to compare these results with the equivalent relationships observed between shareholders and employees in other types of entities. Future research could also examine whether other factors, such as the size of the organization, can influence the existence of harmonious relations.

KEYWORDS: Cooperatives, employment, woman, conciliation, Spain, depopulation. 


\section{1 .- Introducción}

Apenas tres años antes de que en España se aprobase la Ley Orgánica 3/2007, de 22 de marzo, para la igualdad efectiva de mujeres y hombres, y cuatro desde que viera la luz el Informe de 19 de mayo de 2006 del Grupo especial de trabajo sobre buen gobierno corporativo de las sociedades cotizadas $^{1}$, Echebarria y Larrañaga (2004) mantenían que a pesar de las numerosas iniciativas legales y los diversos planes de igualdad puestos en práctica hasta entonces para lograr la correspondencia entre mujeres y hombres, las desigualdades de género en el mundo del trabajo mercantil seguían siendo una realidad. Por este motivo después de varios años de la publicación de la Ley de igualdad, los poderes públicos continúan fomentando el empleo de las mujeres con iniciativas como la aprobación del Plan Estratégico de Igualdad de Oportunidades 2014-2016 (Ministerio de Sanidad, Servicios Sociales e lgualdad, 2014) o la inclusión de recomendaciones más concretas sobre esta materia en el nuevo Código de buen gobierno para las empresas cotizadas (Comisión Nacional del Mercado de Valores, 2015)², cuestión que pone de manifiesto la escasa trascendencia e impacto de la citada ley, como así lo avalan algunos estudios. Es el caso del análisis sobre el estado de la cuestión llevado a cabo por Senent (2011: 80) en el que concluye que "aunque la escasez, fragmentación y relativa antigüedad de los datos desagregados por género no nos deje más que una «foto borrosa y desenfocada» de la situación de las mujeres en las cooperativas, no cabe sino concluir que las mujeres siguen siendo objeto de trato desigual en el sector cooperativo, a pesar de la mayor sensibilidad y tradición de estas organizaciones hacia la no discriminación".

Entre los sectores y estamentos más sensibles a las cuestiones relacionados con la igualdad de género (OIT, 2012) existe una preocupación por el efecto de la recesión económica en la paralización o retroceso en los temas de equidad. Para mitigar las consecuencias de la crisis en su progreso, diversos autores, como Arroyo (2011), insisten en la necesidad de avanzar más rápidamente en la implantación de las políticas precisas para que la ejecución de la Ley de Igualdad prosiga sin retrasos.

En este avance hacia la paridad entre hombres y mujeres en el ámbito laboral se confía a la economía social la eliminación de las desigualdades de género, tal y como se recoge en la Ley 5/2011, de 29 de marzo, de Economía Social. En su artículo 8 se plantea, como uno de los objetivos en las políticas de promoción por parte de los poderes públicos, la implicación de las entidades de la economía social en el empleo, específicamente en el caso de las mujeres, jóvenes y parados de larga

1.- Código unificado de buen gobierno de las sociedades cotizadas (Comisión Nacional del Mercado de Valores, 2006).

2.- El nuevo código de buen gobierno recoge un objetivo concreto para las empresas cotizadas: que en el año 2020 el $30 \%$ del total de miembros del consejo de administración sean mujeres. 
duración, por ser los sectores más afectados por el desempleo. De estos tres grupos, es el de las mujeres el que tiene por objeto este estudio, dado que su manera de trabajar está más cerca de la filosofía y estructura organizativa de las cooperativas que de la de otro tipo de empresas (Ribas y Sajardo, 2005).

Además, el modelo de entidad cooperativa permite a las mujeres afrontar las dificultades desde una mejor posición frente a otras formas más individuales (Nieto, 2006; Okechukwu y Agbodike, 2016). En las cooperativas, las mujeres perciben una oportunidad para desarrollar su perspectiva laboral, adicional al rol de empleadas, mediante la implicación directa en la entidad para desarrollar proyectos empresariales que dan respuesta tanto a sus necesidades como a las de su entorno (Cortés et al., 2008).

Por otro lado, la estructura democrática de las cooperativas permite a las mujeres adquirir experiencia y movilidad en la estructura jerárquica (Chávez, 1996). No obstante, si no se presta atención a las mujeres en las cooperativas, se podrían observar planteamientos discriminatorios que no se corresponderían con los principios y valores cooperativos (Ribas, 2006). Esto llevaría a la pérdida de la identidad y de la esencia de las entidades que conforman el sector de la economía social, constituyendo un caso de incoherencia además de una pérdida de identidad (Ribas, 2013).

Con el fin de avanzar en el conocimiento de la situación de las mujeres en las cooperativas planteamos este artículo que tiene por objetivo analizar las opiniones y percepciones de las mujeres inmersas en el contexto de la economía social, dentro de la provincia de Teruel, en España. De acuerdo con el estudio llevado a cabo por European Spatial Planning Observation Network (ESPON) (2013), esta provincia se encuentra dentro del grupo de regiones con mayor déficit de mujeres entre 20-34 años de toda la Unión Europea, con aproximadamente 80 mujeres por 100 hombres, valor inferior en más de un $10 \%$ a la media de los países de la Unión Europea y la Asociación Europea de Libre Comercio (UE\&EFTA) .

Se pretende conocer, desde el punto de vista de las mujeres, cuáles son los principales beneficios y ventajas que ofrecen estas entidades para su desarrollo familiar, personal y profesional. El mayor conocimiento de los factores sociales y organizativos inherentes a estas organizaciones facilitará el desarrollo de políticas y acciones encaminadas a reforzar proyectos empresariales que contribuyan a integrar las necesidades de las mujeres y las de su entorno.

3.- Véase el informe SEMIGRA - Selective Migration and Unbalanced Sex Ratio in Rural Regions, elaborado en el marco del programa europeo ESPON 2013 (European Spatial Planning Observation Network o Red Europea de Observatorios de Desarrollo Territorial), en el que participa la Comisión Europea y los Estados miembros de la UE27 más Islandia, Liechtenstein, Noruega y Suecia (EPSON, 2013) o el proyecto "empreMter: Mujeres Rurales Emprendedoras en Teruel", desarrollado por la Diputación Provincial de Teruel con el respaldo del Instituto de la Mujer, para aumentar el número de mujeres que inician una actividad empresarial en la provincia y luchar contra la despoblación, http://www.inieu.net/EQUAL/webequal/home.nst/documento/emprendedoras_empremter [Acceso 10 de agosto de 2015]. 
La investigación se organiza de la siguiente manera. Primero se presenta una revisión teórica del papel de las mujeres en las cooperativas. A continuación, el análisis del marco teórico permite fijar el punto de partida para determinar la metodología a seguir en el estudio descriptivo que se muestra en la siguiente sección donde se exponen los principales resultados para, por último, presentar las conclusiones de la investigación.

\section{2.- Barreras y oportunidades de la estructura cooperativa para la igualdad de género}

Las teorías centradas en la aversión al riesgo por parte de las mujeres (Jianakoplos y Bernasek, 1998) sugieren que éstas tienden a ser más conservadoras como emprendedoras que los hombres debido a su mayor aversión (Miller, Burker y Glick, 1998; Anthopoulou, 2010; Koellinger, Minniti y Schade, 2013; Block, Sandner y Spiegel, 2015; Zeffane, 2015). La mayoría de trabajos mencionados muestran que, las mujeres tienden a ser más reacias a asumir riesgo empresarial. Sin embargo, el modelo de entidad cooperativa supone una opción que permite a las mujeres superar las dificultades desde una mejor posición frente a otras tipologías empresariales, como se produciría en el caso de las trabajadoras autónomas (Nieto, 2006). Así se desprende de las conclusiones de la encuesta llevada a cabo por la Confederación Española de Cooperativas de Trabajo Asociado (COCETA), y otras organizaciones cooperativas y sindicatos de Francia e Italia, que a través del proyecto europeo "Mujeres Activas en las PYMES" (www.mujeresactivas.net), confirmaron que en las cooperativas de trabajo de Francia, Italia y España se da una mayor igualdad de género que en las sociedades mercantiles (COCETA 2012). Para Arroyo (2011), una de las ventajas competitivas de las cooperativas de trabajo es la presencia de políticas de conciliación de la vida personal, laboral y familiar lo que lleva a una mayor motivación y productividad en el trabajo.

Otra de las peculiaridades de las cooperativas frente a otras formas jurídicas de empresa, radica en que las normas de autoorganización pueden proporcionar un papel fundamental (Senent, 2011). En estas entidades la dimensión interna de la autogestión está influenciada por la movilización social (Pizzi y Brunet, 2012). En este punto sus diferencias con otro tipo de empresas o de asociaciones radican precisamente en que la cooperativa es una conjunción de dos estructuras, una asociativa basada en reglas democráticas y otra empresarial cuyas normas son fijadas por todas las instancias vinculadas a las actividades económicas integradas por las personas requeridas para su funcionamiento (Richer, 1999; Fernández, Narváez y Senior, 2010).

Esta naturaleza asociativa y empresarial se solapa y refuerza en las cooperativas con la primacía de la organización democrática, pilar básico de los principios cooperativos recogidos por la Alianza Cooperativa Internacional (ACl) (1995). Este carácter asociativo e integrador abarca tanto a los socios y socias como 
al resto del personal de la cooperativa, contribuyendo a mantener ambientes con altos niveles de satisfacción laboral, incluso superiores entre este último colectivo (Gargallo y Freundlich, 2010).

Este tipo de organizaciones pueden estar influidas por la realidad social que las rodea y tener una particular sensibilidad hacia necesidades y problemas sociales (Ribas y Sajardo, 2004; Senent, 2011); y en consecuencia, favorecer la conciliación de la vida familiar y laboral (Chávez, 1996; Gómez, 1998). Es precisamente la organización de la cooperativa la que posibilita la superación de las dificultades vinculadas con los prejuicios de género como es la infravaloración del potencial femenino al frente de un negocio (Cortés et al., 2008).

Al mismo tiempo, la diversidad de género, además de paliar la discriminación, respondiendo a razones de ética empresarial (García-Marzá, 1999), supone una estrategia innovadora (Barberá, 2004) para hacer frente a los nuevos requisitos del mercado de trabajo. La gestión de las empresas mejoraría con organizaciones heterogéneas que incorporasen recursos humanos variados (Berenguer et al., 2004), incrementando la eficiencia de la empresa (Carrasco y Laffarga, 2007). En otro tipo de empresas la evidencia muestra que la diversidad de género en los consejos de administración contribuye a un gobierno corporativo más efectivo (Terjesen, Sealy y Sing, 2009). De acuerdo con Terjesen et al. (2009) las mujeres consejeras contribuyen a la obtención de resultados de gobierno corporativo dentro de la empresa al jugar roles directos como líderes, mentoras o miembros de redes, pero también indirectos al ser símbolos que representan oportunidades para otras mujeres, y que las inspiran para conseguir metas y permanencia en las empresas.

Atendiendo a la teoría de la identidad social, Krishnan y Park (2005) destacan la existencia de un liderazgo femenino diferente al del hombre e indican que la presencia de mujeres en los equipos directivos puede reforzar la cooperación y el trabajo en equipo en la empresa, logrando de este modo mejoras en los resultados de la organización (Gómez Álvarez y Sánchez Barrios, 2009). Sin embargo, distintos estudios evidencian que la participación de las mujeres en la toma de decisiones es menor que la de los hombres, lo que lleva consigo una falta de aprovechamiento del particular estilo directivo femenino (Martínez, Arcas y García, 2011). Si la falta de valoración de aptitudes de las mujeres se produce en el ámbito cooperativo, se está perdiendo un enorme potencial humano e intelectual valioso para el desarrollo de estas entidades (Ribas, 2006).

Para el resto de las empresas, existen numerosos estudios que analizan la presencia de mujeres en altos puestos ejecutivos y su efecto en los resultados. Dwyer, Richard y Chadwick (2003) observaron una relación negativa entre equipos de alta dirección heterogéneos y rentabilidad. Por el contrario, otros estudios evidenciaron una relación positiva entre los equipos de alta dirección diversos y el rendimiento de la firma, argumentando que la diversidad puede intensificar ciertos aspectos como por ejemplo la capacidad del equipo para resolver problemas (Bantel y Jackson, 1989; Hambrick et al., 1996; Smith et al., 1994). Otros trabajos analizan la relación entre la presencia de mujeres en los consejos de administración y la creación de valor, obteniendo resultados diversos, pues algunos resultados asocian la diversidad con rendimientos negativos (Shrader et al., 1997; Pelled et al., 1999; 
Bøhren y Strøm, 2006), otros no encuentran relaciones entre la participación femenina y el rendimiento (Zahra y Stanton, 1988), mientras que otros muchos muestran fuertes lazos entre la participación de las mujeres en los consejos, la rentabilidad y el buen gobierno corporativo (Carter, Simkins y Simpson, 2003; Erhart et al., 2003; Bonn, 2004; Terjesen, Barbosa Couto y Morais Francisco, 2016). En el caso español, Esteban-Salvador (2011) encontró que las medidas de rendimiento no resultaron estadísticamente significativas para predecir una presencia de al menos dos mujeres en el consejo 0 una si es la CEO, pero sí evidenció que las empresas no cotizadas respecto a las cotizadas en el mercado continuo, pertenecientes a los sectores de servicios de consumo e inmobiliario y con alta participación en el capital contribuyeron a detectar una mayor presencia femenina en los consejos. Sin embargo, Campbell y Mínguez-Vera (2008) observaron que una mayor diversidad generó beneficios económicos. En el caso de los consejos de administración de pequeñas y medianas empresas para el periodo 2003-2008, Martín-Ugedo y Mínguez-Vera (2014) evidenciaron relaciones positivas entre la participación de mujeres en los consejos y la rentabilidad de las empresas.

En el caso concreto de las cooperativas españolas los estudios son más escasos, entre ellos se pueden mencionar los de Mateos, Iturroiz y Gimeno (2009), Mateos de Cabo, Gimeno y Escot (2011), Esteban-Salvador (2013) o Hernández-Nicolás, Martín-Ugedo y Mínguez-Vera (2016) entre otros. Esteban-Salvador (2013) observa que entre los consejos corporativos de las principales empresas españolas en 2004 resalta el caso de una cooperativa donde se combinaba una mayor presencia femenina con rentabilidad. En el trabajo de Hernández-Nicolás, Martín-Ugedo y Mínguez-Vera (2016) se analiza la influencia del género en la rentabilidad y en el endeudamiento de las cooperativas y los resultados muestran que la presencia femenina en el consejo rector disminuye el nivel de endeudamiento.

Por otra parte, como señala Ribas (2013: 24), "el objetivo está en la integración y cooperación entre los miembros de uno y otro sexo. Se trata de que hombres y mujeres convivan, coexistan y trabajen juntos; en caso contrario, estamos segregando en un sentido o en otro, a los hombres, a las mujeres 0 a ambos...". Las cooperativas necesitan las capacidades, experiencia y formación de las mujeres (Itkonen, 1995). Pero esa colaboración podría presentar dificultades por la existencia de un techo de cristal definido como un fenómeno mundial que constituye una barrera invisible pero impenetrable que excluye a las mujeres de los altos niveles de la organización (Federal Glass Ceiling Commission, 1997; Burke, 1997; Bell et al., 2002). Estas barreras al acceso de las mujeres a los ámbitos de responsabilidad podrían estar presentes también en las cooperativas. De hecho, voces críticas indican que en este tipo de entidades las mujeres han tenido un papel invisible, subordinado y apenas reconocido, habiendo sido estas excluidas del prestigio y de la autoridad (Apelqvist, 1996).

El devenir histórico revela notables avances en esta materia, mostrando en el último siglo cambios sustanciales en la vida de las mujeres, centrados en todos los ámbitos de la sociedad, debidos a las transformaciones culturales, económicas, tecnológicas y laborales (Cortés et al., 2008).

Desde la perspectiva de género, se han ido corrigiendo desequilibrios en la conquista del mercado, especialmente en la economía social, aunque contrariamente algunos estudios señalan que en las 
cooperativas sigue existiendo el peligro de que las prácticas habituales sobre discriminación sean percibidas como algo generalizado en la sociedad y consideradas como normales si el sector no presta la atención suficiente a la situación laboral de las mujeres (Ribas y Sajardo, 2004). En este sentido, los estereotipos, tradiciones, costumbres y cultura de la sociedad en la que las mujeres están inmersas, son factores que también ejercen influencia en las cooperativas (Senent, 2011).

No hay que olvidar que las entidades que forman parte de la economía social se integran en una sociedad global donde las actuaciones discriminatorias perduran y conviven con modelos de comportamiento en los que prevalecen valores y prácticas discriminatorias (Serra, 2004). De hecho, en los años noventa del siglo XX, Apelqvist (1996), sostenía que la desigualdad de género en estas entidades constituía una gran contradicción entre la teoría y la práctica, hasta tal punto que debilitaba la propia identidad de las cooperativas al prevalecer valores, principios y reglas masculinos concebidos por y para los hombres. Esta afirmación es refrendada por Chaves, Ribas y Sajardo (2005) o por Elío (2006), al añadir que en todas las regiones del mundo estas entidades comparten una característica, y es que con independencia del porcentaje de mujeres trabajadoras que presenten, continúan estando dirigidas por hombres. Ese menor acceso a puestos que permitan adquirir experiencia y formación implicará, así mismo, una menor acumulación de capital humano entre las mujeres. Las teorías sobre el capital humano (Becker, 1964) analizan el papel de las características de los individuos y las capacidades que benefician tanto a los trabajadores que las poseen como a las organizaciones a las que pertenecen, y en base a ellas algunos autores han encontrado que tradicionalmente la inversión en educación y en experiencia laboral en las mujeres ha sido menor que en los hombres y ello se ha traducido en menores oportunidades de promoción o salarios más bajos (Tharenou, Latimer y Conroy, 1994).

La interrelación de las cooperativas con el entorno social y cultural del que forman parte puede conformar al mismo tiempo una virtud y un peligro (Ribas, 2006), la virtud proviene de su mayor sensibilidad hacia los problemas sociales y su mejor capacidad para resolverlos, mientras que el peligro reside en la pérdida de identidad que pueden experimentar al imitar actuaciones habituales en la sociedad que entran en contradicción con los principios cooperativos.

En la misma línea, Senent (2011) mantiene que, pese a la notable sensibilidad y costumbre de las cooperativas hacia la no discriminación de las mujeres, estas entidades continúan tratándolas de modo desigual. Si bien existen indicios de que cuando las empresas utilizan medidas de conciliación de la vida laboral y personal para sus trabajadores, la presencia femenina en los consejos es mayor (Mateos, Iturroiz y Gimeno, 2009).

La mayor parte de los argumentos expuestos relativos a las desigualdades de género entran en contradicción con el espíritu cooperativo donde las decisiones se toman de manera conjunta y no vertical, con independencia del género que las dicte. Para arrojar luz sobre este aspecto, hemos entrevistado a mujeres que forman parte de cooperativas donde la gestión y el trabajo tienen un alto componente femenino. Tratamos de comprobar, por un lado, si la feminización de las cooperativas 
puede facilitar la adopción de políticas y actuaciones vinculadas con la flexibilidad y la conciliación personal, laboral y familiar. Y por otro, si esto puede contribuir a establecer relaciones cercanas con los diferentes agentes del entorno cooperativo. Para ello analizamos, si el estilo de las mujeres está más orientado hacia las necesidades de las personas y es más sensible hacia las cuestiones sociales.

En el Gráfico 1 se aprecia cómo ha evolucionado el empleo femenino en las cooperativas españolas desde que comenzó la crisis. El año 2008 el porcentaje de mujeres trabajadoras en cooperativas era ligeramente inferior al $50 \%$. Sin embargo, a lo largo de los años siguientes se ha producido una evolución creciente, situándose por encima del $50 \%$ en 2009 y alcanzando un porcentaje superior al 52\% en 2014.

\section{Gráfico 1. Porcentaje de mujeres empleadas en cooperativas en España 2008-2014}

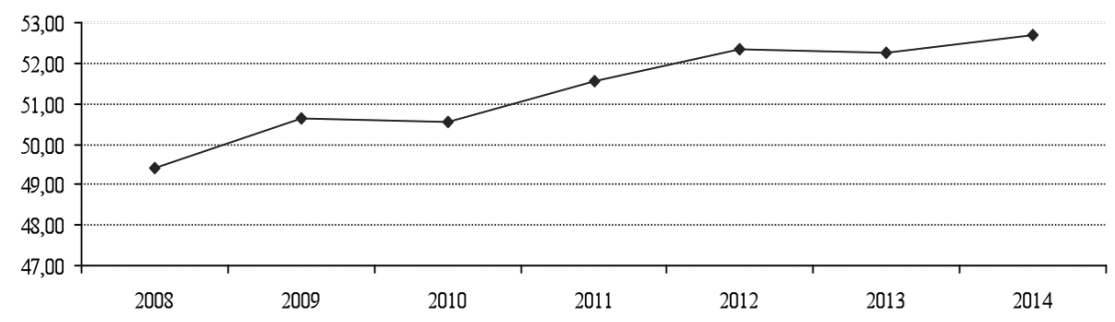

FUENTE: Elaboración propia con datos del Ministerio de Empleo y Seguridad Social (2015).

\section{3.- Metodología}

La metodología utilizada ha sido de tipo cualitativo basada en entrevistas en profundidad (Taylor y Bogdan, 1992), pues ofrece información más precisa y extensa que otras metodologías de investigación alternativas, aportando la flexibilidad necesaria en la recopilación de la información. Para ello se han seleccionado aquellas entidades que hemos catalogado como altamente feminizadas, definiéndolas como aquellas en las que el porcentaje de trabajadoras en su plantilla es mayor que el de trabajadores 0 sus consejos rectores cuentan con mayor proporción de mujeres que de hombres, 0 bien concurren ambas situaciones simultáneamente. A partir de una muestra de 99 cooperativas, que representan el 31,03\% de la población total de entidades cooperativas de la provincia de Teruel, se seleccionaron -siguiendo la metodología aplicada en Esteban, Pérez y Gargallo (2013)-, todas aque- 
llas cooperativas con un componente femenino importante. Las peculiaridades de este territorio, identificadas por el débil tejido empresarial y una baja participación femenina en el mercado laboral ${ }^{4}$, han determinado su elección para este trabajo. Estas características unidas a la despoblación ${ }^{5}$ y a la predominancia del ámbito rural justifican el interés por su estudio, que podría ser replicado en entornos rurales similares. Debido a esta característica de entorno, los resultados pueden venir condicionados por los factores culturales del medio rural, siendo un aspecto que debería tenerse en cuenta en futuras investigaciones que pudieran tomar a este trabajo como referencia. Además, en la provincia de Teruel, donde existe una alta tasa de envejecimiento, bajos índices de población y escasa capacidad de renovación, la articulación entre los aspectos territoriales y estatales es débil (Saz-Gil, Almaguer-Kalixto y Gómez-Quintero, 2016).

Siguiendo el criterio de implicación femenina en cuestiones laborales y de gestión en estas entidades, se identificaron un total de 12 cooperativas con un elevado número de trabajadoras entre su plantilla o con una alta participación femenina en sus consejos rectores, en las cuales se realizaron entrevistas semiestructuradas, una por cooperativa, a socias y/o trabajadoras mediante un cuestionario semiestructurado.

En cuanto a la composición de la estructura societaria de las cooperativas, en dos de los casos analizados (E9 y E10) podría sorprender el alto número de socias. Por una parte, la cooperativa E9, en la cual no hay socios masculinos y, por contra, el número de mujeres socias es de 400 , debido a la peculiaridad de objeto social centrado en la venta al por menor de productos alimenticios para socias y que en sus orígenes fue impulsada por la asociación de amas de casa de la localidad en la que se ubica la cooperativa. Por otra parte, en el caso de la entidad E10, se aprecia que cuenta con solo 70 hombres, mientras que el número de socias asciende a 280 mujeres, siendo en este caso una cooperativa agrícola de producción de aceite, lo que condiciona un empleo fundamentalmente temporal.

De la transcripción de las entrevistas se obtienen interesantes resultados que se presentan manteniendo el anonimato de los informantes. Las respuestas proporcionan evidencia sobre las políticas sociales internas y externas, y sobre las relaciones institucionales y empresariales de estas cooperativas, caracterizadas por una alta presencia de mujeres en su gestión y funcionamiento. Asimismo, el principio de autoorganización en las cooperativas, lleva consigo una gran flexibilidad interna si se comparan con otras fórmulas empresariales.

4.- Aragón se encuentra entre las tres comunidades autónomas españolas con una mayor diferencia de género en la tasa de ocupación y en la tasa de paro entre hombres y mujeres (Ministerio de Empleo y Seguridad Social, 2015). Además, Teruel, en particular, presenta los menores niveles de afiliación femenina de la comunidad (43,62\%, según el Observatorio de las Ocupaciones del Servicio Público de Empleo Estatal, 2015).

5.- Teruel es la segunda provincia más despoblada de España, con 137.838 habitantes (01/01/2015) y una densidad de población de 9,31 hab./Km2 (INE, 2015). 


\section{4.-- Resultados del análisis de las cooperativas con perfil femenino}

Las cooperativas objeto de análisis, anteriormente referenciadas, están ubicadas en la provincia de Teruel. En el Cuadro 1, se especifican sus principales características.

\section{Cuadro 1. Características de las cooperativas altamente femeninas}

\begin{tabular}{|l|c|c|cc|c|cc|c|}
\hline Entrev. & Tipo de actividad & Periodo & \multicolumn{2}{|c|}{$\mathbf{N}^{0}$ de socios } & Familiar & \multicolumn{2}{|c|}{$\mathbf{N}^{0}$ de trabajadores } & \% mujeres \\
& & actividad & Hombres & Mujeres & & Hombres & Mujeres & consejo rector \\
\hline E1 & Hostelería & anual & 1 & 2 & si & 1 & 2 & 66,67 \\
E2 & Agrícola y Ganadera & anual & 1 & 4 & si & 8 & 0 & 80 \\
E3 & Agrícola & anual & 2 & 2 & si & 14 & 2 & 100 \\
E4 & Confección textil & temporada & 0 & 4 & si & 0 & 4 & 100 \\
E5 & Explotación comunitaria de la tierra & anual & 7 & 8 & no & 2 & 0 & 0 \\
E6 & Confección textil & temporada & 0 & 10 & no & 0 & 13 & 100 \\
E7 & Limpieza de edificios y locales & anual & 0 & 5 & no & 0 & 6 & 100 \\
E8 & Confección textil & temporada & 0 & 26 & no & 0 & 42 & 100 \\
E9 & Venta de productos alimenticios & temporada & 0 & 400 & no & 0 & 4 & 100 \\
E10 & Agrícola & anual & 70 & 280 & no & 0 & 4 & 50 \\
E11 & Venta de productos ecológicos & anual & 2 & 3 & no & 0 & 0 & 50 \\
E12 & Confección textil & anual & 0 & 3 & no & 0 & 4 & 100 \\
\hline
\end{tabular}

FUENTE: Elaboración propia.

\section{A. Condiciones de trabajo de las mujeres en las cooperativas}

Las respuestas obtenidas sobre la forma de compaginar la actividad en la cooperativa con la vida familiar, personal y laboral varían según el trabajo en la cooperativa presente el carácter de estacional o continuado. Este aspecto es importante, atendiendo a la mayor intensidad en la contratación femenina en las actividades desarrolladas por campaña, así como por el patrón de temporalidad en algunas de las cooperativas de la provincia. En estudios previos se observan diferencias en la contratación en detrimento de las mujeres en periodos de menor actividad en las cooperativas turolenses (Pérez, Esteban y Gargallo, 2009), así como altos porcentajes de cooperativas agrarias con un desarrollo de su actividad por campaña, donde la contratación más perjudicada en la temporada baja es la femenina (Esteban, Gargallo y Pérez, 2012). 
Igualmente, otros estudios también confirman que las mujeres son más proclives a ser contratadas de forma temporal o a tiempo parcial que los hombres (Chaves et al., 2005; Ribas y Sajardo, 2011; Rico y Gómez, 2011). 6

En el Cuadro 2, se puede apreciar que en periodos de mayor actividad resulta más complicado conciliar la vida personal, familiar y laboral, aunque, por lo general, en las 12 cooperativas referenciadas, las mujeres coordinan bien ambas facetas. Estos resultados están alineadas con las bondades de la autoorganización de este tipo de entidades (Senent, 2011) que permiten una mejor conciliación (Chávez, 1996; Gómez, 1998). Igualmente, cuando se trata de cooperativas familiares los trabajadores suelen complementarse unos a otros, confirmando el compromiso característico de las empresas familiares ligado a su capital humano y social difícil de replicar (Schulze y Gedajovic, 2010).

Varias de las cooperativas ofrecen jornada intensiva, lo que es valorado muy positivamente por las trabajadoras. Así mismo, se comprueba mayores dificultades para conciliar en los periodos de mayor actividad en la cooperativa, tanto en aquellas cooperativas que trabajan por temporada, como en las que indican que su periodo de producción es anual. Medidas encaminadas a la desestacionalización de la demanda, en aquellos sectores en los que esto sea posible, o bien la diversificación en sectores con patrones complementarios en la demanda, podrían contribuir a la mejora de la conciliación.

Esta evidencia obtenida resulta coherente con la sensibilidad de las mujeres hacia la conciliación laboral, como indican Martínez, Arcas y García (2012: 5): "ellas dan prioridad a la conciliación de la vida familiar y profesional". Población Activa, el porcentaje de mujeres con contratos temporales es del $24,1 \%$ frente al $22,2 \%$ en el caso de los hombres y las diferencias en el porcentaje de contratación a tiempo parcial son todavía mayores, siendo del $25,3 \%$ entre las mujeres frente al 7,8\% en el caso de los hombres (INE, 2014). 


\section{Cuadro 2. Conciliación trabajo y vida familiar y personal}

\begin{tabular}{|c|c|}
\hline \multicolumn{2}{|r|}{ ¿Cómo compagina usted la actividad en la cooperativa con su vida familiar? } \\
\hline 1 & Bien, entre los socios se reparten las horas y el trabajo en el bar para poder atender a la familia. \\
\hline 2 & $\begin{array}{l}\text { Las mujeres no trabajan de modo continuado en la granja, pero le dedican todo el tiempo que pueden por lo que } \\
\text { a temporadas es poco compatible, en las fechas de mucha actividad pasan más tiempo con los animales que con } \\
\text { sus familias. El trabajo en la agricultura es muy esclavo, y poco compatible con la vida familiar. }\end{array}$ \\
\hline 3 & $\begin{array}{l}\text { Más o menos es llevadero y al ser todos los miembros familia trabajan complementándose los unos a los otros } \\
\text { cuando hace falta. Si uno necesita un día o dos libres o se pone enfermo, sus socios lo sustituyen sin problemas. }\end{array}$ \\
\hline 4 & $\begin{array}{l}\text { Hacen poca vida en casa no se les acaba la jornada nunca, y no saben vivir con trabajo pendiente. Los encargos } \\
\text { que les hacen los han de trabajar rápido para mantener contento al cliente y no perderlo, no pueden dormirse, } \\
\text { porque si no salen perdiendo ellas. }\end{array}$ \\
\hline 5 & La vida familiar la llevan como pueden pero les va bien, aún tienen tiempo para pasarlo con su familia. \\
\hline 6 & $\begin{array}{l}\text { Llevan jornada intensiva de trabajo, tienen las tardes libres, y aún en las temporadas de mucho trabajo lo } \\
\text { compaginan bien. }\end{array}$ \\
\hline 7 & $\begin{array}{l}\text { Ella lo compagina bien, ya que sus hijos son mayores, cuando eran más pequeños lo compatibilizaba bien porque } \\
\text { ella se iba a limpiar cuando estaban en el colegio. }\end{array}$ \\
\hline 8 & $\begin{array}{l}\text { Lo compaginan bastante bien porque el horario es flexible, partido y limitado a } 8 \text { horas. Por este motivo se combina } \\
\text { bien. }\end{array}$ \\
\hline 9 & Todas sus trabajadoras son mujeres maduras que están contentas, y no han pedido reducciones de jornada nunca. \\
\hline 10 & $\begin{array}{l}\text { Como pueden. En la temporada de recogida de oliva muy mal, las jornadas son muy largas, aunque sólo duran unos } \\
\text { meses. El resto del año, concilian muy bien la vida familiar y laboral. }\end{array}$ \\
\hline 11 & $\begin{array}{l}\text { Solo abren un día a la semana y de momento el trabajo de los socios en la cooperativa se realiza esporádicamente } \\
\text { y de forma voluntaria, turnándose los días de trabajo que abren la tienda. Pero ella al ser la responsable de la } \\
\text { cooperativa, le dedica a la misma más tiempo del que quisiera, tiempo que pierde de estar en su casa. }\end{array}$ \\
\hline 12 & Trabajan con jornada intensiva, tienen las tardes libres. \\
\hline
\end{tabular}

FUENTE: Elaboración propia.

Esta evidencia obtenida resulta coherente con la sensibilidad de las mujeres hacia la conciliación laboral, como indican Martínez, Arcas y García (2012: 5): "ellas dan prioridad a la conciliación de la vida familiar y profesional".

En cuanto a los horarios de trabajo, las entrevistas revelan que las trabajadoras están satisfechas y asimilan la distribución temporal del tiempo de trabajo. (Cuadro 3). Las épocas de mucha actividad las perciben como una oportunidad, no como un problema, por lo que no les importa adaptar los horarios de trabajo 0 incluso dedicar más horas si es necesario. Las cooperativistas coinciden en afirmar que si el negocio funciona no tienen inconveniente en ampliar horas, e incluso ante horarios comerciales abiertos al público consideran que este debe ser más dilatado. 


\section{Cuadro 3. Horarios de trabajo}

\begin{tabular}{|c|c|}
\hline $\begin{array}{l}\text { ¿Qué opinión tienen acerca de } \\
\text { los horarios de trabajo? }\end{array}$ & $\begin{array}{l}\text { En momentos de mucha producción, ¿se adaptan estos horarios? } \\
\text { ¿Qué implicaciones tiene en su vida familiar? }\end{array}$ \\
\hline $\begin{array}{l}\text { E1. No quieren que les falte trabajo, por lo que } \\
\text { cuanto más trabajen mejor. }\end{array}$ & $\begin{array}{l}\text { En temporadas con mayor intensidad productiva pasan menos tiempo en } \\
\text { casa y ello influye en el núcleo familiar. Las épocas de mucha actividad } \\
\text { las ven como una oportunidad, no como un problema. }\end{array}$ \\
\hline $\begin{array}{l}\text { E2. Están acostumbrados a jornadas } \\
\text { interminables }\end{array}$ & $\begin{array}{l}\text { Sí los adaptan, sobre todo en verano están menos en casa, la familia está } \\
\text { acostumbrada. }\end{array}$ \\
\hline E3. Buena, ya que se los organizan a su gusto. & $\begin{array}{l}\text { Sí que adaptan los horarios. Cuando hace falta se hacen más horas, pero } \\
\text { eso no pasa mucho. }\end{array}$ \\
\hline $\begin{array}{l}\text { E4. Son muy largos en épocas de mucha faena, } \\
\text { pero se alegran cuando el negocio funciona. }\end{array}$ & $\begin{array}{l}\text { En temporadas altas pasan menos tiempo en casa y estas épocas son } \\
\text { una oportunidad para la cooperativa. Si necesitan ausentarse del trabajo } \\
\text { lo pueden hacer. }\end{array}$ \\
\hline $\begin{array}{l}\text { E5. Siempre se adaptan. Ahora no hay trabajo por } \\
\text { lo que no pueden valorar los horarios de trabajo. }\end{array}$ & $\begin{array}{l}\text { Sí, cuando han tenido que trabajar muchas horas lo han hecho, a su } \\
\text { familia les han tenido acostumbrados a esos horarios. }\end{array}$ \\
\hline $\begin{array}{l}\text { E6. Muy buenos y ello les ayuda a la hora de } \\
\text { planificarse con las tareas del hogar. }\end{array}$ & $\begin{array}{l}\text { En las temporadas muy fuertes trabajan más para sacar todo el trabajo } \\
\text { en su debido tiempo. }\end{array}$ \\
\hline $\begin{array}{l}\text { E7. Les parecen muy buenos ya que se } \\
\text { organizan como quieren. }\end{array}$ & $\begin{array}{l}\text { Hacen más horas cubriendo la faena como pueden, no les implican } \\
\text { mucho. }\end{array}$ \\
\hline E8. Le parecen bastante buenos y llevaderos. & $\begin{array}{l}\text { temporadas muy fuertes pasan menos tiempo en casa y ello influye, } \\
\text { ro necesitan trabajar. }\end{array}$ \\
\hline E9. Son de tipo comercial, los aceptan. & $\begin{array}{l}\text { Se adaptan los horarios por la mañana, en temporadas fuertes se } \\
\text { contrata a trabajadores adicionales. }\end{array}$ \\
\hline $\begin{array}{l}\text { E10. En temporada alta son intempestivos, } \\
\text { el trabajo no se reparte regularmente a lo largo } \\
\text { del año. }\end{array}$ & $\begin{array}{l}\text { Sí que se adaptan, las jornadas son larguísimas y dependen de cómo } \\
\text { vaya el año. }\end{array}$ \\
\hline $\begin{array}{l}\text { E11. Buena, solo trabajan un día a la semana } \\
\text { y cada semana le toca a un socio. }\end{array}$ & $\begin{array}{l}\text { Sí, pero hay socios menos responsables y, dejan más trabajo a los demás, } \\
\text { sobre todo los hombres. Además no son ellos los que han de prestar } \\
\text { atención a su casa. }\end{array}$ \\
\hline $\begin{array}{l}\text { E12. Muy buena, el horario les ayuda planificarse } \\
\text { con las tareas del hogar. }\end{array}$ & $\begin{array}{l}\text { En temporadas muy fuertes si hace falta hacen más horas, pero lo } \\
\text { compaginan bien. }\end{array}$ \\
\hline
\end{tabular}

FUENTE: Elaboración propia.

En la mayoría de los casos no hay trabajadoras con reducción de jornada, únicamente en una cooperativa, dos socias trabajan a media jornada. En el caso de cooperativas familiares, se organizan la jornada distribuida entre los trabajadores si es necesario para atender a la actividad productiva. De las respuestas se puede deducir que, en general, si las trabajadoras necesitan reducción de jornada no encuentran dificultades en sus empresas debido a la propia organización de las tareas, mientras que en las sociedades mercantiles más alejadas de la filosofía cooperativista, este tipo de cuestiones 
serían más complicadas de resolver. Este resultado asiente con una mayor predisposición del género femenino para acogerse a jornadas reducidas (Abril et al., 2015; Pellejà-Ciurana, 2015).

Abordando la cuestión relativa al disfrute del periodo vacacional, en el Cuadro 4 se puede apreciar que en general este depende de la actividad concreta de la cooperativa, presentando facilidades para la distribución de los turnos. Se evidencia que "parecen ponerse fácilmente de acuerdo", pero en algún caso se manifiestan ciertas preferencias de las trabajadoras frente a las socias: "...Los trabajadores disfrutan de las vacaciones, los socios no..." (E2).

\section{Cuadro 4. Elección del periodo vacacional}

\begin{tabular}{|c|c|c|c|}
\hline & $\begin{array}{l}\text { ¿Tienen facilidad para escoger su periodo de } \\
\text { vacaciones? }\end{array}$ & $\begin{array}{l}\text { Si es así, ¿Cómo se reparten los } \\
\text { turnos vacacionales entre los } \\
\text { socios? }\end{array}$ & $\begin{array}{l}\text { ¿Quién tienen preferencia para ele- } \\
\text { gir las vacaciones, las socias o las } \\
\text { trabajadoras? }\end{array}$ \\
\hline E1 & $\begin{array}{l}\text { En temporada de poco trabajo se cierra la coo- } \\
\text { perativa y cogen las vacaciones todas a la vez. }\end{array}$ & $\begin{array}{l}\text { Todos los socios se acogen al mismo } \\
\text { turno. }\end{array}$ & $\begin{array}{l}\text { No procede porque no hay asalaria- } \\
\text { dos. }\end{array}$ \\
\hline E2 & $\begin{array}{l}\text { Nunca han tenido } 2 \text { semanas enteras de vacacio- } \\
\text { nes, se ayudan para compaginar los descansos. }\end{array}$ & $\begin{array}{l}\text { Si alguien necesita algún día, avisa y } \\
\text { lo sustituyen. }\end{array}$ & $\begin{array}{l}\text { Los trabajadores disfrutan de las } \\
\text { vacaciones, los socios no. }\end{array}$ \\
\hline E3 & $\begin{array}{l}\text { No toman vacaciones, tienen unos pocos días } \\
\text { cuando les conviene, al ser familia no tienen pro- } \\
\text { blemas. }\end{array}$ & $\begin{array}{l}\text { Cuando hay huecos se distribuyen las } \\
\text { vacaciones cada uno como y cuando } \\
\text { más les conviene. }\end{array}$ & $\begin{array}{l}\text { No hay problema porque no se cogen } \\
\text { vacaciones cuando están trabajando. }\end{array}$ \\
\hline E4 & $\begin{array}{l}\text { Dependen de sus clientes y las toman todas a la } \\
\text { vez porque el trabajo es en cadena. }\end{array}$ & $\begin{array}{l}\text { Todas las socias las toman las vaca- } \\
\text { ciones a la vez. }\end{array}$ & $\begin{array}{l}\text { No procede contestar, no tienen tra- } \\
\text { bajadores asalariados. }\end{array}$ \\
\hline E5 & $\begin{array}{l}\text { Nunca se han disfrutado de un mes entero de } \\
\text { vacaciones, no tienen muchos problemas para } \\
\text { tener alguna semana de descanso. }\end{array}$ & $\begin{array}{l}\text { El único socio que trabaja en la coo- } \\
\text { perativa es él. }\end{array}$ & $\begin{array}{l}\text { Los pocos trabajadores las cogen } \\
\text { cuando pueden. }\end{array}$ \\
\hline E6 & $\begin{array}{l}\text { Todas las socias se ciñen a los } 3 \text { meses de cie- } \\
\text { rre al año. Durante los periodos de producción no } \\
\text { tienen vacaciones. }\end{array}$ & $\begin{array}{l}\text { Todas las socias disfrutan de las vaca- } \\
\text { ciones a la vez, ya que el trabajo es en } \\
\text { cadena. }\end{array}$ & $\begin{array}{l}\text { Socias y trabajadoras, descansan en } \\
\text { los mismos periodos de trabajo. }\end{array}$ \\
\hline E7 & $\begin{array}{l}\text { Se las cogen cuando quieren, distribuyéndolas } \\
\text { entre ellas. }\end{array}$ & $\begin{array}{l}\text { Siempre se suelen poner todas de } \\
\text { acuerdo. }\end{array}$ & $\begin{array}{l}\text { No hay diferencias entre socias y tra- } \\
\text { bajadoras. }\end{array}$ \\
\hline E8 & $\begin{array}{l}\text { Todas se cogen las vacaciones a la vez, cierran } \\
\text { cuando tienen menos faena, el trabajo es en } \\
\text { cadena. }\end{array}$ & $\begin{array}{l}\text { Las socias y las trabajadoras las } \\
\text { toman a la vez. }\end{array}$ & $\begin{array}{l}\text { Las socias trabajadoras las toman a } \\
\text { la vez, cuando la temporada se lo } \\
\text { permite. }\end{array}$ \\
\hline E9 & $\begin{array}{l}\text { En julio y agosto no pueden tener vacaciones } \\
\text { porque hay mucha gente en el pueblo; navidad } \\
\text { tampoco pero el resto del año no hay problema. }\end{array}$ & $\begin{array}{l}\text { Como las socias no trabajan, las vaca- } \\
\text { ciones se las reparten y se suelen } \\
\text { organizar bastante bien. }\end{array}$ & $\begin{array}{l}\text { No procede contestar a esta pre- } \\
\text { gunta por qué no tienen hay socias } \\
\text { directivas que trabajen. }\end{array}$ \\
\hline E10 & $\begin{array}{l}\text { En verano no trabajan casi, cada uno las coge } \\
\text { cuando le conviene pero en temporada alta no } \\
\text { las disfruta nadie. }\end{array}$ & $\begin{array}{l}\text { Bien porque solo trabajan unos tres } \\
\text { meses al año. }\end{array}$ & $\begin{array}{l}\text { Los trabajadores solo trabajan en } \\
\text { temporada. }\end{array}$ \\
\hline E11 & $\begin{array}{l}\text { No hay nadie contratado. Trabajan un día a la } \\
\text { semana y se turnan. }\end{array}$ & $\begin{array}{l}\text { Cuando se las conceden en su trabajo } \\
\text { particular, sin tener en cuenta su acti- } \\
\text { vidad en la cooperativa. }\end{array}$ & $\begin{array}{l}\text { No procede contestar a esta pre- } \\
\text { gunta, porque los socios no trabajan } \\
\text { en la cooperativa. }\end{array}$ \\
\hline E12 & $\begin{array}{l}\text { Cierran la cooperativa, y cesan la actividad en } \\
\text { alguna época "floja" todas las socias a la vez. }\end{array}$ & $\begin{array}{l}\text { Todas las socias se disfrutan de las } \\
\text { vacaciones a la vez, ya que el trabajo } \\
\text { es en cadena. }\end{array}$ & $\begin{array}{l}\text { Socias y trabajadora descansan en } \\
\text { los mismos periodos vacacionales. }\end{array}$ \\
\hline
\end{tabular}

FUENTE: Elaboración propia. 
Respecto a las consideraciones sobre las mejoras en el trabajo (Cuadro 5), en algunos casos las encuestadas sostienen que si se incrementase el volumen de actividad en la cooperativa, las horas trabajadas serían más eficientes. No obstante, parece que las mejoras en la productividad podrían venir dadas en mayor medida por la innovación y la intensificación de capital. A pesar de la mayor aversión femenina al riesgo (Jianakoplos, y Bernasek, 1998) y por ello a la realización de innovaciones que supongan incrementar la inversión, las trabajadoras de una de las cooperativas indican que deberían apostar por la innovación de procesos y la introducción de máquinas y equipos más eficientes que facilitarían a su vez mejoras en la gestión y organización. Generalmente, además son conscientes de que necesitarían realizar mayores esfuerzos en publicidad, aprovechado las posibilidades que brindan las nuevas tecnologías. Si bien las cooperativistas analizadas ofrecen una opción para el desarrollo personal y social, se comprueba que también muestran interés por la mejora y la búsqueda de la eficiencia organizacional, aspecto coherente con la necesidad de competir en el mercado con las empresas capitalistas.

\section{Cuadro 5. Aspectos para mejorar el trabajo}

\begin{tabular}{|l|l|}
\hline \multicolumn{2}{|l|}{ ¿Cómo consideran que podrían mejorar el trabajo en la cooperativa? } \\
\hline E1 & Incrementando el nivel de actividad, así las horas trabajadas serían más eficientes. \\
E2 & Contratando a más trabajadores y vendiendo más barato. \\
E3 & Se consideran eficientes y en el pueblo están contentos con ellos. \\
E4 & Si incrementara más la actividad, trabajarían con más ilusión y con más ganas de mejorar. \\
E5 & Con la concentración parcelaria, hubieran rendido mucho más todas sus tierras. \\
E6 & Son bastante eficientes y consideran que aprovechan muy bien sus recursos. \\
E7 & No se ven deficiencias. \\
E8 & Innovando en máquinas, en equipos eficientes, y publicitándose más usando nuevas tecnologías. \\
E9 & Con un local más grande se trabajaría mejor. \\
E10 & Si no les exigieran tantos trámites y papeleo, tasas, etc. funcionarían más ágiles, además tienen que realizar \\
& las mismas cargas y trámites que una gran cooperativa con elevado volumen de trabajo. \\
E11 & Contratando a alguien que llevara y trabajara en la tienda, así ellos no se implicarían tanto. \\
E12 & Consideran que aprovechan muy bien sus recursos. Al ser tan pocas no pueden trabajar de otra forma. \\
\hline
\end{tabular}

FUENTE: Elaboración propia.

\section{B. Relaciones con agentes internos y externos}

Respecto al desarrollo de las relaciones internas y externas de la cooperativa, los resultados destacan la existencia de un buen clima laboral y un entorno colaborativo en el que se desenvuelven. Mayoritariamente no se detecta conflictividad entre los trabajadores de la cooperativa y los socios trabajadores. Por lo general, además de no existir conflictos sociales entre ambos, estos mantienen una buena relación laboral. Todas las encuestadas destacan que se llevan bien o muy bien con sus com- 
pañeras y compañeros y los comentarios adicionales van en la línea de lo que indicaba otra de las encuestadas. La explicación de esta actuación descansa en el modelo de gestión cooperativa basado en "acuerdos sociales" gestionados democráticamente por el conjunto de socios, en lo relativo a cuestiones de dirección como en las de tipo laboral.

En la tarea directiva de organizar/distribuir el trabajo, tampoco parecen existir grandes diferencias entre las socias y las trabajadoras (Cuadro 6). Algunas mujeres señalan que existe igualdad laboral entre socias y trabajadoras. En algunos casos las decisiones las toma el consejo rector, pero teniendo previamente en cuenta la opinión de los trabajadores. En este aspecto se consignan grandes diferencias con las relaciones organizativas de otro tipo de empresas, lo que unido a la presencia de un estilo de liderazgo femenino, más enfocado a la cooperación y el trabajo en equipo (Krishnan y Park, 2005), permite comprender los resultados mostrados.

\section{Cuadro 6. Interrelación dirección-trabajadora}

\begin{tabular}{|l|l|}
\hline \multicolumn{3}{|l|}{ ¿Las socias se consideran como una jefa u órgano de dirección o como una trabajadora más? } \\
\hline E1 & Todos los socios trabajan por igual pero parece que la mayor responsabilidad recae en el hijo. \\
E2 & Los socios dirigen la actividad en la granja, y trabajan más que los empleados. \\
E3 & Los socios se consideran como un trabajador más pero distribuyendo el trabajo entre todos. \\
E4 & Entre las cuatro deciden y trabajan por igual cada una en su parte del proceso productivo. \\
E6 & Las decisiones las toman en el consejo rector y después plantean y marcan las directrices a los trabajadores. \\
E7 & Existe igualdad entre ellas, pero las trabajadoras cobran siempre y las socias hay meses que no. \\
E8 & Todas son trabajadoras, no hay diferencias ni en el trato ni en el trabajo. \\
E9 & Todo se decide por en la asamblea, a través del consejo rector. La opinión de los trabajadores es tenida en cuenta. \\
E10 & Todos trabajan por igual, la dirección de la cooperativa trabaja mucho y se consideran trabajadores y no jefes. \\
E11 & Todos los socios mandan y deciden por igual sin haber diferencias entre ellos. \\
E12 & Las socias se consideran una trabajadora más, todas incluso las trabajadoras mandan por igual. \\
\hline
\end{tabular}

FUENTE: Elaboración propia.

El grado de rivalidad de las cooperativas analizadas, con otras empresas del sector donde operan, es en general bajo, bien porque no existen otras empresas competidoras directas que desarrollen la misma actividad, o bien porque las cooperativas han logrado una alta diferenciación de su producto o servicio. En el Cuadro 7, se puede apreciar que, por lo general, las cooperativas seleccionadas presentan buenas relaciones entre ellas, buscando en muchos casos sinergias y complementariedades que refuercen sus posiciones competitivas frente a otras empresas que no presentan este modelo de empresa. 


\section{Cuadro 7. Relaciones con la competencia}

\begin{tabular}{|l|l|}
\hline \multicolumn{2}{|l|}{ ¿Cómo se llevan ustedes con la competencia? } \\
\hline E1 & Se llevan bien, se ayudan los unos a los otros, van a su marcha y cada uno que haga lo que pueda. \\
E2 & Se intentan llevar bien pero siempre hay roces inevitables con la competencia. \\
E3 & Por la zona donde está ubicada apenas tienen competencia, no se hacen daño porque hay pocos que trabajen la patata. \\
E4 & Cuando necesitan algo se ayudan. Generalmente cada empresa se centra en un producto, no se hacen la competencia. \\
E5 & No tienen competencia con otras cooperativas, se llevan bien. \\
E6 & Se llevan bien, cuando se necesitan se ayudan. No se hacen la competencia. \\
E7 & No tienen competencia porque no hay más empresas de limpieza que le trabajen para el ayuntamiento. \\
E8 & Allí no tienen competencia, en la provincia cada cooperativa se dedica a una cosa. \\
E9 & No se llevan mal, pero tampoco se ayudan los unos a los otros. No pueden obviar a la competencia. \\
E10 & Se llevan bien, se ayudan los unos a los otros. No pueden ser competitivos con las grandes cooperativas del sector. \\
E11 & Se llevan bien, en su día se ayudaron con otra empresa que ahora ya no existe, complementándose. \\
E12 & Se llevan bien y cuando se necesitan se ayudan unas cooperativas a otras. No se hacen la competencia. \\
\hline
\end{tabular}

FUENTE: Elaboración propia.

Analizando los datos relativos a las ayudas o subvenciones recibidas debido a la característica de ser una cooperativa formada por mujeres, socias o trabajadoras, en varios casos se observa que han percibido alguna ayuda por ser mujeres, empresarias mayores de 45 años, y sobre todo la percepción de ciertas ayudas por ser mujeres en el momento inicial de constitución de la cooperativas (Cuadro 8). En algunas cooperativas no han recibido ninguna subvención por no cumplir los requisitos exigidos por la legislación correspondiente.

\section{Cuadro 8. Ayudas o subvenciones}

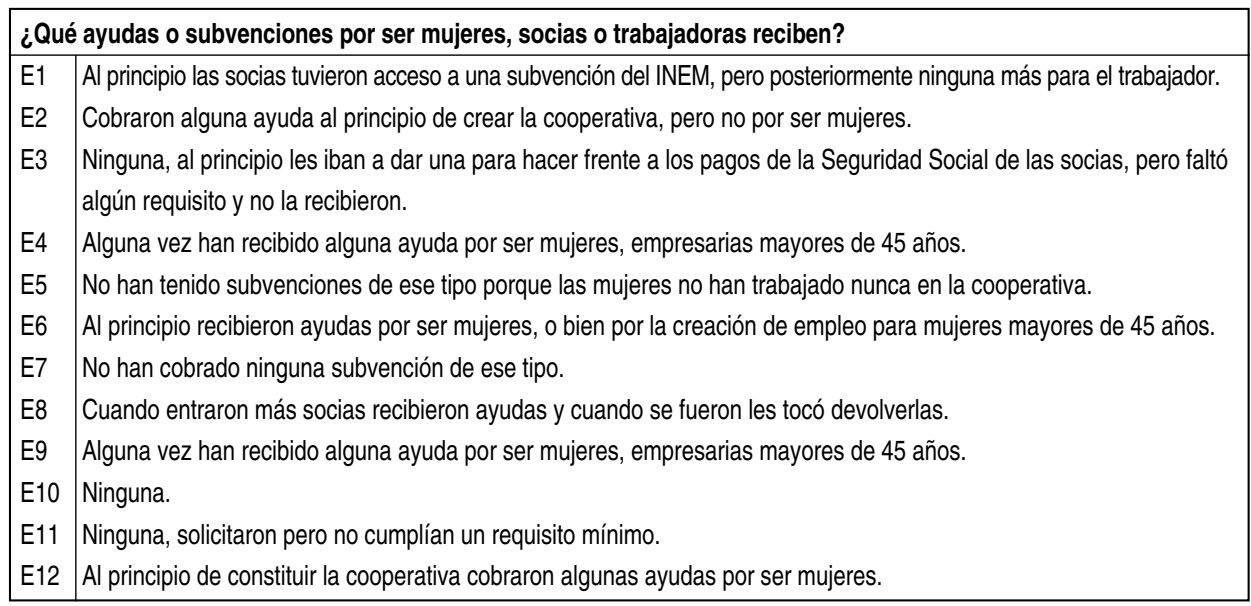

FUENTE: Elaboración propia.

CIRIEC-España, Revista de Economía Pública, Social y Cooperativa

ISSN: 0213-8093

№ 88/2016, pp. 61-92 


\section{Beneficio económico versus beneficio social}

Por lo general el salario percibido por las trabajadoras, especialmente en el caso de las mujeres casadas, no es considerado como el ingreso principal de la familia, sino como una ayuda que complementa los ingresos familiares, cuestión que enfatiza con el rol o identidad de género (perspectiva sociológica de estructura social). Para las mujeres de las cooperativas entrevistadas las posibilidades que el puesto de trabajo ofrece para su compaginación con la vida familiar son casi tan importantes como el salario, contrariamente a la posición de los hombres (Instituto de la Mujer, 2005). Lo mismo sucede en el caso de una trabajadora que siendo soltera vive con los padres (Cuadro 9). Estos resultados están en línea con los obtenidos por Cortés et al. (2008), en los que se evidencia que es escaso el impacto de los ingresos de la cooperativa en la economía familiar, y además refuerzan la idea del tradicional reparto de roles entre hombres y mujeres, siendo los primeros los encargados de aportar la estabilidad económica a la unidad familiar frente al valor secundario de la contribución femenina (Moreno et al., 1999).

Solamente en una de las cooperativas trabaja una mujer soltera, en cuyo caso el salario sí que supone la principal fuente de ingresos. Igualmente, cuando la cooperativa es familiar y cuenta con hombres los ingresos suelen ser el sustento principal. En el caso de las socias de las cooperativas los resultados coinciden con la variable anterior en gran medida.

\section{Cuadro 9. Ingresos}

\begin{tabular}{|l|l|l|}
\hline & $\begin{array}{l}\text { En su caso personal, ¿su salario supone la renta principal } \\
\text { en su familia, o es una ayuda? }\end{array}$ & ¿Y en el caso de sus socias? \\
\hline E1 & Sí que supone la renta principal de su familia. & Ídem. \\
E2 & Sí supone la renta principal de la familia. & Para alguno sí, para otros es una ayuda. \\
E3 & Es el sustento principal de las familias de los 4 socios. & Ídem. \\
E4 & Es una ayuda, el sustento principal lo proporciona el marido. & Ídem para todos menos para una soltera. \\
E5 & Él es el padre de familia y sí es la renta principal. & No trabajan directamente. \\
E6 & Es una ayuda, la renta principal la aporta el marido. & Ídem. \\
E7 & Supone una ayuda, la renta principal la aporta el marido. & Ídem. \\
E8 & Está soltera y vive con los padres: Lo considera una ayuda. & Suele ser un apoyo económico. \\
E9 & Solo una está soltera y supone la renta principal. & No contesta. \\
E10 & Es una ayuda, no tienen salario, solo los excedentes cooperativos. & Ídem. \\
E11 & Ahora, todo son pérdidas, ni siquiera es una ayuda. & Ídem. \\
E12 & Es una ayuda, la renta principal la aporta el marido. & Ídem. \\
\hline
\end{tabular}

FUENTE: Elaboración propia. 
Más allá de los ingresos monetarios obtenidos de su participación en la cooperativa, en la pregunta relativa a los beneficios que la cooperativa aporta a las socias (Cuadro 10), se observa que, en general, existe gran satisfacción por desarrollar el trabajo bajo su propia dirección, de forma autogestionada, sin un jefe que les transmita órdenes. Desarrollan la actividad con más entusiasmo y motivación, puesto que consideran a la cooperativa como su propia empresa, hasta tal punto que muchas de las socias y empleadas trabajan para sentirse realizadas principalmente, ya que económicamente no lo necesitan. La cooperativa les aporta gran satisfacción personal, de modo que aunque algunas socias presentan edades avanzadas se siguen sintiendo útiles y realizadas. En otros casos les ayuda además a sentirse independientes. Este resultado entronca con la orientación de las mujeres hacia el trabajo productivo (Lipovetsky, 2003: 87) en un marco de búsqueda y construcción autónoma de la identidad: "en la idea del trabajo existe algo más que el propio deseo de escapar del aburrimiento de la vida familiar, existe además la exigencia de afirmar la identidad de persona y construir e inventar su propia vida".

\section{Cuadro 10. Beneficios de la cooperativa}

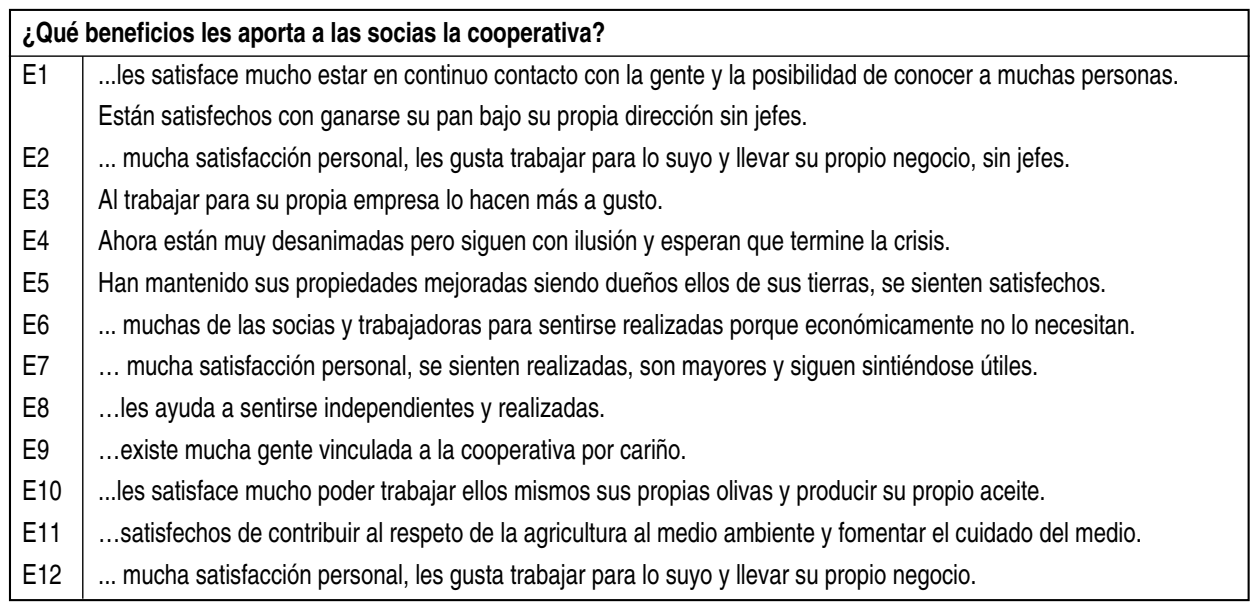

FUENTE: Elaboración propia.

Aunque en ocasiones el beneficio económico obtenido sea bajo, las socias dan más importancia a los resultados sociales proporcionados por la cooperativa. Se constata que los objetivos sociales se anteponen a la maximización del beneficio económico o utilidad, como apuntan Ribas y Sajardo (2004). Estos resultados coinciden con los de Cortés et al. (2008), quienes observaron que las cooperativas fortalecen la autoestima de las mujeres y crean las condiciones para mejorar su calidad de vida. 
Respecto a las ventajas o desventajas que proporciona una cooperativa formada mayoritariamente por mujeres se aprecian de nuevo los principios y valores cooperativos que rigen estas entidades (Cuadro 11).

\section{Cuadro 11. Ventajas y/o desventajas de ser cooperativa formada mayoritariamente por mujeres}

\begin{tabular}{|l|l|}
\hline \multicolumn{3}{|l|}{ ¿Qué ventajas o desventajas tiene una cooperativa formada mayoritariamente por mujeres? } \\
\hline E1 & La cooperativa se creó de forma familiar, son más mujeres socias por casualidad. \\
E2 & Desventajas ninguna, lo único que el hombre se carga más, sus hijas al tener hijos no han podido trabajar. \\
E3 & Es importante la opinión de la mujer porque son más listas, se siente muy orgulloso de sus socias. \\
E4 & Ventajas ninguna, desventajas muchas. Por ser mujer tienen más obligaciones y menos tiempo para el hogar. \\
& Después de trabajar no descansan y sufren más estrés que los hombres, ellos sí que descansan. \\
E5 & Circunstancialmente han sido las viudas las que a lo largo de los años han ocupado el sitio de sus maridos \\
& por lo que esa es la razón de la mayoría de mujeres en esta cooperativa. \\
E6 & No encuentra ninguna ventaja o desventaja importante por ser mujeres todas las socias. \\
E7 & A ello no le aprecia ninguna desventaja. \\
E8 & Para ella todo son ventajas, no tienen jefes, no han sufrido exclusión o discriminación. \\
E9 & Desventajas ninguna, las socias tienen bastantes ventajas por su condición, no por la de ser mujer. \\
E10 & Ninguna como los maridos son prejubilados ponen a la mujer pero trabajan más ellos. \\
E11 & Solo le cabe decir que las mujeres son más responsables y trabajadoras que los socios que son hombres. \\
E12 & La familia y las cargas familiares les limitan el trabajo, esa es la única desventaja por ser mujeres. \\
\hline
\end{tabular}

FUENTE: Elaboración propia.

Una de las mujeres encuestadas afirma que no encuentra inconvenientes ya que las socias tienen bastantes ventajas adquiridas con la condición de socio, y no por la condición de mujer. En este caso concreto se podría pensar en una discriminación en razón de la posición de cooperativista o no cooperativista dentro de la organización y no por género, si bien podría ser un caso aislado.

La mayoría de las mujeres entrevistadas piensan que en la cooperativa, por su propia filosofía, no existe discriminación. Así se observa en algunas de las repuestas: "...desventajas ninguna, las socias tienen bastantes ventajas por su condición, no por la de ser mujer..." (E9).

“...para mí todo son ventajas, no tenemos jefes y no hemos sufrido exclusión o discriminación...” (E8).

Por lo que también se puede observar el principio de igualdad; en contraposición a la respuesta de la anterior entrevistada. Lo que se constata con mayor abundancia son roles patriarcales en la conciliación de la vida familiar y personal, generalmente más que en la faceta laboral. Una respuesta que pone de manifiesto que el hecho de ser mujer sigue estando presente en la conciliación familiar, la expresa una de las trabajadoras con las siguientes palabras: 
“...ventajas ninguna, desventajas muchas. Por ser mujer tienes más obligaciones y menos tiempo para el hogar. Después de trabajar no descansas y sufres más estrés que los hombres, ellos sí que descansan..." (E4).

"...la familia y las cargas familiares limitan mucho el trabajo en la cooperativa, esa es la única desventaja que pueden ver por el hecho de ser mujeres..." (E12).

\section{5.- Conclusiones}

En este estudio se han abordado aspectos relacionados con las condiciones laborales y de flexibilidad en el trabajo de las mujeres en las cooperativas. El estudio de las cuestiones de género en la gestión de empresas resulta importante tanto por sus implicaciones desde un punto de vista de equidad y justicia social, como por las implicaciones económicas de la diversidad de género en las organizaciones.

Los resultados de los análisis nos indican que uno de factores que incide en la conciliación de la vida familiar, personal y laboral es la presencia de estacionalidad o no en las actividades desarrolladas en la cooperativa. Esta cuestión resulta especialmente relevante, atendiendo al perfil mayoritariamente femenino de la contratación temporal en España. Por tanto, medidas internas encaminadas a la desestacionalización de la demanda, podrían contribuir tanto a la mejora de la conciliación como a la reducción de las desigualdades entre hombres y mujeres.

En cuanto a las condiciones de trabajo, destacan las oportunidades de conciliación y de flexibilidad horaria, apoyadas en la buena voluntad y en el clima de confianza existente en las cooperativas. Esta cuestión está muy relacionada con las buenas relaciones entre sus miembros, tal y como se desprende de las opiniones de las encuestadas y con la presencia de un liderazgo femenino enfocado en una mayor colaboración y trabajo en equipo. Resulta destacable que estas relaciones cordiales se extienden incluso entre las empresas del sector, siendo frecuentes las actitudes colaborativas entre cooperativas del mismo sector de actividad.

La autogestión permite que la reducción de jornada se adapte a las propias necesidades de las trabajadoras con mayor facilidad que con otra fórmula empresarial. Lo mismo ocurre con los horarios de trabajo, ya que entienden que son ellas las que deben adaptarse a las necesidades de los clientes, y conciben que trabajar más horas es un aspecto positivo, al considerar que ello significa que el negocio funciona. Por lo general, los horarios no son motivo de preocupación. Son conscientes de que si la actividad requiere una mayor dedicación de horas, su implicación debe ser mayor, ya que de la supervivencia de la cooperativa depende su futuro laboral. 
En cuanto a la conflictividad laboral no se detectan problemas entre las trabajadoras y las socias, presentando una relación cordial entre ellas. Sería interesante para futuros estudios, comparar estos resultados con las relaciones equivalentes observadas entre accionistas y trabajadores en otro tipo de entidades de carácter estrictamente mercantil. Asimismo se podría analizar si otros factores, como el tamaño de la organización pueden influir en la existencia de relaciones armoniosas.

También son reseñables las buenas relaciones existentes entre las diferentes cooperativas de la provincia. Los análisis destacan el establecimiento de relaciones de apoyo mutuo con otras cooperativas y, en muchos casos, el aprovechamiento de complementariedades con las empresas de la competencia. Esta cuestión refuerza los comportamientos previstos para las cooperativas basados en la intercooperación y el trabajo en redes.

En este sentido, dadas las peculiaridades del contexto donde actúan estas cooperativas, mayoritariamente en el entorno rural, les permiten cubrir las necesidades de los socios, dinamizar el desarrollo rural, mejorar las actividades comerciales, facilitar el apoyo y asesoramiento para el acceso a nuevos mercados exteriores, mejorar las estructuras mediante procesos de integración (cooperativas de $2^{\circ}$ grado y grupos cooperativos), y la obtención de ventajas competitivas con fórmulas de intercooperación con otros grupos.

Respecto al apoyo de la administración en aspectos relacionados con trámites, información o asesoramiento, no se han obtenidos resultados concluyentes. Las relaciones con las administraciones públicas, sin embargo, podrían mejorarse para aprovechar todo el potencial de creación de riqueza en las cooperativas y para lograr una mayor eficacia de las políticas de apoyo público al emprendimiento femenino y de promoción de las entidades de la economía social.

Como indican varias cooperativistas, los excesivos trámites administrativos les obligan a recurrir a expertos externos e incluso han impedido en algunos casos que hayan podido aprovechar las medidas de estímulo y apoyo empresarial vía subvenciones. Dado el reconocimiento por parte de las autoridades gubernamentales españolas de las desigualdades de género en el ámbito laboral y empresarial, expresado a través de las medidas de fomento de la paridad entre hombres y mujeres en la Ley de igualdad, se debería prestar atención a los procedimientos administrativos de las cooperativas por ser más sensibles a las mujeres que otros tipos de entidades.

La simplificación de los trámites administrativos y el asesoramiento a las emprendedoras sociales debería contemplarse en las agendas de los poderes públicos para apoyar a las mujeres con iniciativas empresariales. Estas medidas se tornan especialmente sensibles en territorios como es el caso de la provincia analizada donde la debilidad de su tejido empresarial y el desempleo femenino son componentes claros de su estancamiento económico. Las subvenciones no parece que sean un aspecto decisivo para la creación y el mantenimiento de la cooperativa, aunque algunas de las entidades sí obtuvieran apoyo económico en el momento de su constitución. 
Se puede apreciar claramente cómo los principios cooperativos se encuentran presentes en estas entidades, como es el caso de una de ellas donde los socios están satisfechos y contentos de contribuir al respeto de la agricultura y del medio ambiente y de fomentar el cuidado del medio.

Más allá de los ingresos monetarios vinculados con la participación en la cooperativa, cabe destacar otros beneficios no económicos de carácter "intangible" relacionados con la satisfacción y la realización personal derivada de esa participación. Este valor añadido debe ser tenido también en cuenta a la hora de cuantificar los beneficios de las cooperativas y de la economía social en su conjunto, y sobre todo en el momento de formular su estrategia y valorar los resultados conseguidos.

En las cooperativas constituidas, paritaria o mayoritariamente, por mujeres, por lo general está presente la filosofía y los valores de actuación cooperativos, apreciándose en algún caso las ventajas por la condición de socia con independencia de que sea mujer y la no discriminación de género. Por tanto, pueden señalarse factores vinculados a las relaciones horizontales dentro de la organización como condicionantes del valor de la igualdad y el principio de participación democrática y no tanto distinciones de género entre las cooperativas estudiadas.

A pesar de ello, se aprecia que queda todavía un camino importante que recorrer para alcanzar la conciliación de la vida personal, familiar y laboral que permita lograr la plena igualdad. Esta cuestión revela la necesidad de actuaciones, tanto institucionalmente mediante medidas de fomento, como internamente en las propias entidades a través de incentivos conducentes a la aplicación plena de estas reglas de conducta cooperativas.

\section{Referencias}

ABRIL, P., AMIGOT, P., BOTÍA-MORILLAS, C., DOMÍNGUEZ-FOLGUERAS, M., GONZÁLEZ, M.J., JURADO-GUERRERO T., LAPUERTA, I., MARTÍN-GARCÍA, T., MONFERRER, J. \& SEIZ M. (2015): "Ideales igualitarios y planes tradicionales: Análisis de parejas primerizas en España". Reis: Revista Española Investigación Social, 150, 3-22.

ALIANZA COOPERATIVA INTERNACIONAL (ACI) (1995): "Los principios cooperativos del siglo XXI", CIRIEC-España, Revista de Economía Pública, Social y Cooperativa, 19, 38-39.

ANTHOPOULOU, T. (2010): "Rural women in local agrofood production: Between entrepreneurial initiatives and family strategies. A case study in Greece", Journal of Rural Studies, 26(4), 394-403.

APELQVIST, K. (1996): "Estrategias para una autoridad compartida entre hombres y mujeres en las cooperativas", Revista de Cooperación Internacional, 1, 35-47. 
ARROYO, P. (2011): "Perfil de la situación de la mujer en las cooperativas de trabajo en España", REVESCO, Revista de Estudios Cooperativos, 105, 115-142.

BANTEL, K.A. \& JACKSON, S.E. (1989): "Top management and innovations in banking: Does the composition of the top team make a difference?", Strategic Management Journal, 10, 107-124.

BARBERÁ, E. (2004): "Diversidad de género, igualdad de oportunidades y entornos laborales (La diversidad de género como estrategia favorecedora de la igualdad de oportunidades en los entornos laborales)", CIRIEC-España, Revista de Economía Pública, Social y Cooperativa, 50, 37-53.

BECKER, G. (1964): Human Capital. A Theoretical and Empirical Analysis, with Special Reference to Education, University of Chicago Press, Chicago.

BELL, M.P., MCLAUGHLIN, M.E. \& SEQUEIRA, J.M. (2002): "Discrimination, harassment, and the glass ceiling: women executives as change agents", Journal Business Ethics, 37, 65-76.

BERENGUER, G., CERVER, E., DE LA TORRE, A. \& TORCAL, V.R. (2004): "El estilo directivo de las mujeres y su influencia sobre la gestión del equipo de trabajo en las cooperativas valencianas", CIRIEC-España, Revista de Economía Pública, Social y Cooperativa, 50, 123-149.

BLOCK, J., SANDNER, P. \& SPIEGEL, F. (2015): "How do risk attitudes differ within the group of entrepreneurs? The role of motivation and procedural utility", Journal of Small Business Management, $53,183-206$.

BONN, I. (2004): "Board Structure and Firm Performance: Evidence from Australia", Journal of Management \& Organization, 10(1), 14-24.

BØHREN, Ø. \& STRØM, R. Ø. (2006): "Aligned, informed and decisive: Characteristics of value creating Boards", Working paper, Norwegian School of Management.

BURKE, R.J. (2000): "Women on Canadian corporate boards of directors: Still a long way to go". En R.J. Burke y M.C. Mattis (Eds.), Women on corporate boards of directors, Kluwer Academic Publishers, The Netherlands, 97-109.

CAMPBELL, K. \& MÍNGUEZ VERA, A. (2008): "Gender diversity in the boardroom and firm financial performance", Journal of Business Ethics, 83, 435-451.

CARRASCO, A. \& LAFFARGA, J. (2007): "La diversidad de género en el Código Unificado español y la práctica empresarial", Pecvnia, 4, 1-25.

CARTER, D.A., SIMKINS, B.J. \& SIMPSON, W.G. (2003): "Corporate governance, board diversity, and firm value", The Financial Review, 38, 33-53.

CHAVES, R., RIBAS, M. \& SAJARDO, A. (2005): "Cumplimiento del primer principio: análisis de la discriminación por género en las cooperativas españolas", Revista de la Cooperación Internacional, 38 (1), 101-118. 
CHÁVEZ, M. (1996): "El papel de la ACl en el progreso de la mujer en las cooperativas", Revista de la Cooperación Internacional, 1, 51-62.

COMISIÓN NACIONAL DEL MERCADO DE VALORES (2006): Informe del grupo especial de trabajo sobre buen gobierno corporativo de las sociedades cotizadas, de 19 de mayo de 2006, CNMV, España.

COMISIÓN NACIONAL DEL MERCADO DE VALORES (2015): Código de buen gobierno de las sociedades cotizadas, CNMV, España.

CONFEDERACIÓN ESPAÑOLA DE COOPERATIVAS DE TRABAJO ASOCIADO (COCETA) (2012): Mujeres activas en las PYMES: Estudio transnacional sobre los acuerdos y las medidas innovadoras para favorecer la participación de la mujer en las Pymes, COCETA, España.

CORTÉS, D., LÓPEZ, C., ORTIZ, N. \& PÉREZ, A. (2008): "Emprendurismo en mujeres, cooperativismo y cultura organizacional: desarrollos teóricos y evidencia empírica", En: Emprendurismo, cultura, clima y comunicación organizacional y su aplicación a la pequeña y mediana empresa en la Zona Metropolitana de Guadalajara, México. Editado por Rigoberto Soria Romo, 96-135. EUMEDNET Universidad de Málaga, España.

DWYER, S., RICHARD, O.C. \& CHADWICK, K. (2003): "Gender diversity in management and firm performance: the influence of growth orientation and organizational culture", Journal of Business Research, 56(12), 1009-1019.

ECHEBARRIA, C. \& LARRAÑAGA, M. (2004). "La igualdad entre mujeres y hombres: una asignatura pendiente", CIRIEC-España, Revista de Economía Pública, Social y Cooperativa, 50, 11-35.

ELGART, L.D. (1981): "Women in the 'Top 500' Boardrooms: A Hint of Optimism”, Academy of Management Proceedings, 397-401.

ELÍO, E. (2006): "Responsabilidad social en las cooperativas: igualdad de oportunidades entre hombres y mujeres", Revista Vasca de Economía Social, 2, 35-71.

ESPON (2013): SEMIGRA Selective Migration and Unbalanced Sex Ratio in Rural Regions. Targeted Analysis 2013/2/15 Final Report, Main Report and Scientific Report, European Observation Network for Territorial Development and Cohesion.

ESTEBAN, M.L. (2011): "Variables influencing the gender composition of boards: The Spanish evidence", Journal of Women, Politics \& Policy, 32(4), 305-332.

ESTEBAN, M.L. (2013): “¿Son las cooperativas más favorables a la presencia de mujeres en los consejos que otras entidades?", REVESCO, Revista de Estudios Cooperativos, 110, 96-128.

ESTEBAN, L., PÉREZ, F. \& GARGALLO, A. (2013): "Mujer y cooperativas: un análisis cualitativo a través del estudio de un caso", VII Coloquio Ibérico Internacional de Cooperativismo y Economía Social Sevilla, 19 y 20 de septiembre, 2013. 
ESTEBAN, L., GARGALLO, A. \& PÉREZ, F. (2012): "El papel de la mujer en las cooperativas agrícolas turolenses", CIRIEC-España, Revista de Economía Pública, Social y Cooperativa, 74, 177 205.

FEDERAL GLASS CEILING COMMISSION (FGCC) (1997): The glass ceiling. En: Dunn, D. (Ed.). Workplace/women's place: an anthology, Los Angeles, CA, Roxbury Publishing, 226-233.

FERNÁNDEZ, G., NARVÁEZ, M. \& SENIOR, A. (2010): "Organizaciones cooperativas en el contexto del desarrollo local: una aproximación para su estudio", Revista Venezolana de Gerencia, 49, 87-102.

GARCÍA-MARZÁ, D. (1999): "Mujer y entorno empresarial", Papeles de Ética, Economía y Dirección, $4,1-14$.

GARGALLO, A. \& FREUNDLICH, F. (2010): "Percepciones de los socios y no socios cooperativistas sobre la satisfacción laboral", REVESCO, Revista de Estudios Cooperativos, 103, 33-58.

GÓMEZ, L. (1998). "Women in Co-operatives: The Policy of the International Cooperative Alliance", Journal of Co-operative Studies, 93, 33-56.

GÓMEZ ÁLVAREZ, J. \& SÁNCHEZ BARRIOS, M. (2009): "La participación de la mujer en los consejos de administración de empresas del Ibex-35", Revista de Humanidades, 16, 1130-5029.

KRISHNAN, H. \& PARK, D. (2005): "A few good women - on top management teams", Journal of Business Research, 58(12), 1712-1720.

HAMBRICK, D.C., CHO, T.S. \& CHEN, M.J. (1996): "The influence of top management team heterogeneity on firms' competitive moves", Administrative Science Quarterly, 41, 659-684.

HERNÁNDEZ-NICOLÁS, C.M., MARTÍN-UGEDO, J.F. \& MÍNGUEZ-VERA, A. (2016): "La influencia del género en la dirección de las sociedades cooperativas españolas sobre la rentabilidad y el riesgo: un análisis empírico", REVESCO, Revista de Estudios Cooperativos, pendiente de publicación, http://pendientedemigracion.ucm.es/info/revesco/ArticulosAprobados.php.

INSTITUTO NACIONAL DE ESTADÍSTICA (2014): Encuesta de población activa 2014. http://www.ine.es.

INSTITUTO NACIONAL DE ESTADÍSTICA (2015): Cifras de población y Censos demográficos. http://www.ine.es.

INSTITUTO DE LA MUJER (2005): Conciliación de la vida familiar y la vida laboral: Situación actual, necesidades y demandas (Informe de resultados), Observatorio 7. http://www.migualdad.es/mujer.

ITKONEN, R. (1995): "Perspectivas de género en los informes de la ACI Europa", Revista de la Cooperación Internacional, 28, 2, 68-78.

JIANAKOPLOS, N. \& BERNASEK, A. (1998): "Are women more risk averse?", Economic Inquiry, 36(4), 620-630. 
KOELLINGER, P., MINNITI, M. \& SCHADE, C. (2013): "Gender differences in entrepreneurial propensity", Oxford Bulletin of Economics and Statistics, 75(2), 213-234.

Ley Orgánica 3/2007, de 22 de marzo, para la igualdad efectiva de mujeres y hombres, Boletín Oficial del Estado, n 71, de 23 de marzo de 2007, España.

Ley 5/2011, de 29 de marzo, de Economía Social, Boletín Oficial del Estado, $n^{\circ}$ 76, de 30 de marzo de 2011, España.

LIPOVETSKY, G. (2003): "La familia ante el reto de la tercera mujer: amor y trabajo", II Congreso la familia en la sociedad del siglo XXI, Fundación de Ayuda contra la Drogadicción..

MARTÍNEZ, I., ARCAS, N. \& GARCÍA, M. (2011): "La influencia del género sobre la responsabilidad social empresarial en las entidades de economía social", REVESCO, Revista de Estudios Cooperativos, 105, 143-172.

MARTÍNEZ, I., ARCAS, N. \& GARCÍA, M. (2012): "Influencia de la igualdad de género en la responsabilidad social empresarial. Una aplicación en las entidades de economía social", Boletín del Centro de Investigación de Economía y Sociedad, 96, 1-26.

MARTÍN-UGEDO, J.F. \& MÍNGUEZ-VERA, A. (2014): "Firm performance and women on the board: Evidence on Spanish small and medium-sized enterprises", Feminist Economics, 20(3), 136-162.

MATEOS DE CABO, R., ITURROIZ DEL CAMPO, J. \& GIMENO NOGUÉS, R. (2009): "La participación financiera y el papel de la mujer en la toma de decisiones de las sociedades cooperativas: los consejos de administración", Revista Europea de Dirección y Economía de la Empresa, 18(3), 65-82.

MATEOS DE CABO, R., GIMENO, R. \& ESCOT, L. (2011): "Disentangling discrimination on Spanish boards of directors", Corporate Governance: An International Review, 19(1), 77-95.

MILLER, C., BURKER, L. \& GLICK, W. (1998): "Cognitive diversity among upper-echelon executives: Implications for strategic decision processes", Strategic Management Journal, 19(1), 39-58.

MINISTERIO DE EMPLEO Y SEGURIDAD SOCIAL (2015): La situación de las mujeres en el mercado de trabajo en 2014, Secretaría de Estado de Empleo.

MINISTERIO DE SANIDAD, SERVICIOS SOCIALES E IGUALDAD (2014): Plan Estratégico de Igualdad de Oportunidades 2014-2016, Instituto de la Mujer y para la Igualdad de Oportunidades.

MORENO, M.J., AGIRREGOMEZKORTA, R.B. \& CUADRADO, M. (1999): Manual para la introducción de la perspectiva de género y juventud al desarrollo rural, Junta de Andalucía, Consejería de Agricultura y Pesca, Andalucía.

NIETO, C. (2006): "Las mujeres y el cooperativismo en los procesos de desarrollo local. Algunos ejemplos de la provincia de Málaga", Documents d'anàlisi Geogràfica, 47, 31-52. 
OBSERVATORIO DE LAS OCUPACIONES DEL SERVICIO PÚBLICO DE EMPLEO ESTATAL (2015): Informe del Mercado de Trabajo de las Mujeres. Estatal. Datos 2014, Servicio Público de Empleo Estatal.

OKECHUKWU, E.O. \& AGBODIKE, F.C. (2016): "Strategy for women development in Anambra State, Nigeria: Co-Operative societies' option", Review of Public Administration and Management, 5, 105114.

ORGANIZACIÓN INTERNACIONAL DEL TRABAJO (OIT) (2012): Plan de acción de la OIT sobre la igualdad de género 2010-2015, Ginebra.

PELLED, L.H., EISENHARDT, K.M. \& XING, K.R. (1999): "Exploring the black box: An analysis of work group diversity, conflict, and performance", Administrative Science Quarterly, 44, 1-28.

PÉREZ, F., ESTEBAN, L. \& GARGALLO, A. (2009). "Participación, gobierno democrático y resultados cooperativos: una perspectiva de RSE", CIRIEC-España, Revista de Economía Pública, Social y Cooperativa, 65, 163-192.

PIZZI, A. \& BRUNET, I. (2012): "Acción colectiva, autogestión y economía social. El caso de las empresas recuperadas en Argentina", Revista de Estudios Sociales, 42, 57-70.

PELLEJÀ-CIURANA, M.A. (2015): La conciliación de la vida laboral y familiar en las mujeres españolas. Determinantes de la satisfacción según la intensidad de los ciudadanos en la sociedad del conocimiento, Tesis doctoral. Universistat Oberta de Catalyunya.

RIBAS, M. (2013): "La desigual participación de hombres y mujeres en la economía social", IX Congreso estatal Isonomia sobre Igualdad entre Mujeres y Hombres, Emprendimiento con perspectiva de género en la economía social, Publicacions de la Universitat Jaume I, Castellón.

RIBAS, M. \& SAJARDO, A. (2004): "La desigual participación de hombres y mujeres en la economía social: teorías explicativas", CIRIEC-España, Revista de Economía Pública, Social y Cooperativa, 50, 77-103.

RIBAS, M. \& SAJARDO, A. (2005): "La diferente participación laboral de las mujeres entre las cooperativas y las sociedades laborales", CIRIEC-España, Revista de Economía Pública, Social y Cooperativa, 52, 267-278.

RIBAS, M. \& SAJARDO, A. (2011): "Desigualdad de género en tiempos de crisis: análisis comparativo de la economía social", REVESCO, Revista de Estudios Cooperativos, 105, 34-56.

RIBAS, M. (2006): "Mujeres y cooperativismo en la Comunidad Autónoma del País Vasco", Revista Vasca de Economía Social, 2, 153-175.

RICHER, M. (1999): "Lo distintivo de las organizaciones cooperativas", Revista Venezolana de Gerencia, 8, 11-27. 
RICO, M. \& GÓMEZ, J.M. (2011): "Economía social e igualdad de oportunidades en el ámbito rural. Un análisis aplicado a la comunidad autónoma de Castilla y León", REVESCO, Revista de Estudios Cooperativos, 105, 85-114.

SAZ-GIL, I., ALMAGUER-KALIXTO, P. \& GÓMEZ-QUINTERO, J.D. (2016): "Social capital and networks: analysis of the Third Sector in rural contexts", CIRIEC-España, Revista de Economía Pública, Social y Cooperativa, 86, 123-154.

SCHULZE, W.S. \& GEDAJLOVIC, E. (2010): "Whither Family Business?", Journal of Management Studies, 47(2), 191-204.

SENENT, M. (2011): “¿Cómo pueden aprovechar las cooperativas el talento de las mujeres? Responsabilidad social empresarial e igualdad real", REVESCO, Revista de Estudios Cooperativos, 105, 57-84.

SERRA, I. (2004): "Las políticas públicas de igualdad en el empleo y la economía social y cooperativa", CIRIEC-España, Revista de Economía Pública, Social y Cooperativa, 50, 105-122.

SHRADER, C.B., BLACKBURN, V.B. \& ILES, P. (1997): "Women in management and firm financial performance: an exploratory study", Journal of Managerial Issues 9(3), 355-372.

SMITH, K.G., SMITH, K.A., OLIAN, J.D., SIMS, H.P. Jr., O'BANNON, D.P. \& SCULLY, J.A. (1994): "Top management team demography and process: the role of social integration and communication", Administrative Science Quarterly, 39, 412-38.

TAYLOR, S.J. \& BOGDAN, R. (1992): Introducción a los métodos cualitativos en investigación. Editorial Paidós, Barcelona.

TERJESEN, S., SEALY, R. \& SINGH, V. (2009): "Women directors on corporate boards: A review and research agenda", Corporate Governance: An International Review, 17(3), 320-337.

TERJESEN, S., BARBOSA COUTO, E. \& MORAIS FRANCISCO, P. (2016): "Does the presence of independent and female directors impact firm performance? A multi-country study of board diversity", Journal of Management \& Governance, 20(3), 447-483.

THARENOU, P., LATIMER, S. \& CONROY, D. (1994): "How to make it to the top? An examination of influences on women's and men's managerial advancement", Academy of Management Journal, $37,899-931$.

ZAHRA, S.A. \& STANTON, W.W. (1988): "The implications of board of directors' composition for corporate strategy and value", International Journal of Management, 5(2), 229-236.

ZEFFANE, R. (2015): "Trust, personality, risk taking and entrepreneurship: Exploring gender differences among nascent and actual entrepreneurs in the United Arab Emirates", World Journal of Entrepreneurship, Management and Sustainable Development, 11(3), 191-209. 